\title{
Renewable Energy Development in China: Spatial Clustering and Socio-Spatial Embeddedness
}

\author{
Ping Huang ${ }^{1}$ - Ying Liu ${ }^{2}$
}

Published online: 17 April 2017

(C) The Author(s) 2017. This article is an open access publication

\begin{abstract}
Purpose of review In the past decade, China has made remarkable achievements in the development of renewable energies. This article adopts a geographical perspective for China's current wave of renewable energy transitions, by viewing the transition outcomes through the lenses of spatial clustering and socio-spatial embeddedness.

Recent findings We find that many renewable energy industry clusters have emerged nationwide and different patterns are uncovered for the clustering in extant literature, either through bottom-up agglomeration around pioneering enterprises, or driven by top-down government strategy and planning. There is scant research on the reconfiguration of sociospatial arrangements, which is an important but very often neglected facet of energy transitions. We further discuss the regional disparities in China's renewable energy development, in which resource-rich regions are mainly in the north part of China, while central, eastern, and southern regions possess substantial advantages in fostering industry clusters.

Summary In the end, we propose two avenues for future research: firstly, to explore why different clustering patterns emerge in a certain region but not in another, and what implications these cases of clustering can draw for other regions in China or other latecomer countries; secondly, to uncover how
\end{abstract}

This article is part of the Topical Collection on Regional Renewable Energy (China)

Ping Huang

p.huang@ucl.ac.uk; huang_ping1987@hotmail.com

1 Bartlett Development Planning Unit, University College London, 34 Tavistock Square, London WC1H 9EZ, UK

2 Department of Human Geography and Planning, Faculty of Geosciences, Utrecht University, 3508 TC Utrecht, The Netherlands renewable energy application and popularization shape local socio-spatial arrangements.

Keywords Renewable energy $\cdot$ Industrial clustering $\cdot$ Energy infrastructure $\cdot$ Built environment $\cdot$ Social practice $\cdot$ Culture of consumption

\section{Introduction}

Climate change has become a high-profile issue in the past decade. As the largest greenhouse gas (GHG) emitter in the world, China has played an irreplaceable role in the task of combating climate change. In 2015, China announced the "Enhanced Actions and Measures on Climate Change", in which it has set the goal of lowering carbon dioxide emissions per unit of GDP by 60 to $65 \%$ from the 2005 level. To achieve this goal, it necessitates fundamental changes in current coalbased energy systems. In January 2017, the Chinese government published the "13th Five-Year Development Plan for Renewable Energy (2016-2020)", and it is estimated that till 2020 a total investment of 2.5 trillion CNY (about US\$0.4 trillion) will be allocated to the development of renewable energy. Against this background, a much more rapid transition toward renewable energy-based energy system in China is seemingly taking shape.

Energy transitions refer to radical, large-scale, and integrated socio-technical changes in energy systems. Thus, the field of transitions aims to capture the co-dynamics of energy related technologies, institutions, social, and economic sub-systems, which has greatly contributed to the understanding of temporal process of energy transitions and has explained how the emergence and development of new energy technologies can occur in a specific place, e.g., a country [1-4]. However, extant studies tend to overlook the diversity of sub-national 
contexts, and are criticized against simplifying and mechanizing the role of local contextual factors in energy transitions process $[1,5,6]$. In recent years, the concrete spatial contexts within which transitions take place are increasingly recognized in energy and transition studies [7-10]. It is related to this "spatial turn" that in this review article on renewable energy development in China, we take a geographical perspective, by addressing the socio-spatial manifestations of renewable energy transitions.

\section{Renewable Energy Development in China}

In the past decade, China has made significant progress in the development of renewable energies. The annual consumption of renewable energy has increased from 166.00 million tce in 2005 to 512.48 million tce in 2015 . In the newly released " 13 th Five-Year Development Plan for Renewable Energy (20162020)", the annual consumption of renewable energy has been planned to reach 729.28 million tce in 2020. Table 1 presents the main indicators for the development of renewable energy in China in the past decade. These promising figures indicate China's rapid transition to a more sustainable energy system.

Different from previous review articles that usually investigate Chinese renewable energy development from production and consumption scale, policy, or investment (see for instance $[13,14])$, we adopt a geographical perspective for China's current wave of renewable energy transitions. Bridge et al. (2013) argued that "energy transition is fundamentally a geographical process that involves reconfiguring current spatial patterns of economic and social activity" (p. 331) [5]. The strong connection between energy transitions and pre-existing geographical configurations, energy accessibility, and the transformation of spatial arrangement of the built environment demonstrates that the understanding of transitions (especially radical transitions toward renewable energy systems) requires situating them within spatial contexts, alongside material, and physical components of local energy systems. Following Bridge et al.'s (2013) understanding of geography of transitions, combined with evolutionary economic geography perspective of transitions (Truffer and Coenen, 2012) $[5,6]$, we regard the spatial clustering and socio-spatial embeddedness as two main dynamic trends/ outcomes of renewable energy development and transitions. It is worth noting that this conceptual framing of energy transitions outcome is not exhaustive, but is illustrative in essence.

\section{Formation and Development of Industrial Clusters}

We regard the formation and development of spatial industry clusters as one of the two main manifestations for a sustainable energy transition. Spatial clustering reflects the geographical agglomeration of an emergent industry, which is usually associated with renewable energy development in a region, by integrating into pre-existing relevant industry cluster (for example, biofuel and chemical cluster in Stenungsund, Sweden), or by forming a new cluster that surrounds high-tech renewable energy technologies (for example, wind turbine cluster in Jiangsu, China) [15-17]. Against the background of rapid growth of China's renewable energy sectors, many studies have documented the emergence and evolution of renewable energy clusters.

One typical case for the development of solar energy is Shandong province, in which a well-known industry cluster has formed. It is home to Himin, the world's largest solar water heaters (SWH) manufacturer [18]. In 2013, there were more than 300 SWH manufacturers in Shandong, with an annual output of more than 10 million heaters, comprising over $40 \%$ of the total production output of the country. A complete industry chain, covering the production of silica sand, rough pipe, vacuum tube, heat collector, and heat collecting system, has been established within the solar thermal power industry. Among the ten representative SWH enterprises in China summarized by $\mathrm{Hu}$ et al. (2012), half are located in Shandong province. Strong industrial foundation plays an imperative role in promoting the use of solar energy
Table 1 China's renewable energy development in the 11 th and 12 th five-year period

\begin{tabular}{lrrr}
\hline & 2005 & 2010 & 2015 \\
\hline Annual consumption of renewable energy (million tce) & 166.00 & 286.00 & 512.48 \\
Share of renewable energy in the total energy consumption (\%) & 7.50 & 8.90 & 10.10 \\
Installed capacity of hydropower (GW) & 117.39 & 216.06 & 319.54 \\
Installed capacity of grid-connected wind power (GW) & 1.26 & 31.00 & 129.00 \\
Installed capacity of solar PV power (GW) & 0.07 & 0.80 & 43.18 \\
Annual consumption of solar water heaters (million m $^{2}$ ) & 80.00 & 168.00 & 440.00 \\
Installed capacity of biomass power (GW) & 2.00 & 5.50 & 10.30 \\
Annual consumption of biogas (billion m ${ }^{3}$ ) & 8.00 & 14.00 & 19.00 \\
Annual consumption of biomass fuel (million tons) & 1.07 & 2.30 & 2.90 \\
Annual consumption of geothermal power (million tce) & 2.00 & 4.60 & 4.60 \\
\hline
\end{tabular}

Sources: $[11,12]$ 
[19]. The application of solar energy is very advanced in many cities in Shandong province, such as Rizhao and Dezhou [20]. Solar energy is not only penetrated into local people's everyday life, but is also widely applied in other industries such as paper making, machinery, and textiles [18].

Another typical case is the development of wind power industry in Jiangsu province. He et al. (2016) gave a detailed discussion on wind industry clusters in Jiangsu province. Specifically, three clusters within Jiangsu province have emerged: Yancheng, Nantong, and Lianyungang. The authors revealed the evolution process of the three clusters, in which a relatively complete wind power equipment industry chain has taken shape, including blades, gearboxes, generators, bearings, towers, and control systems [16].

Bringing together wind and solar power industry, Dong et al. (2016) analyzed the spatial distribution of China's renewable energy industry. Based on spatial analysis on the output value, they identified four renewable energy clusters in China: (1) Bohai rim areas, includes Beijing, Tianjin, Heibei, Shandong, etc.; (2) Yangtze River Delta region, includes Shanghai, Jiangsu, Zhejiang, Fujian, etc.; (3) Middle China region, includes Henan, Jiangxi, etc.; (4) western China region, includes Sichuan, Inner Mongolia, Xinjiang, Gansu, etc. Two clusters are located in eastern China, one in central China, and one in western China [21].

From these studies, different patterns of cluster formation can be observed. In the case of solar industry in Shandong, pioneering enterprises such as Himin have played an important role during the early stage of cluster emergence, since "successful imitation is most likely to take place in close geographical proximity to the pioneering firms" (p. 924) [22]. While in the case of wind industry clustering in Jiangsu, local governments have acted as a strong enabling factor, either by initiating the construction of wind farms, or by planning large wind power related industrial parks. Along with the development of a cluster, various types of externalities may come into being that further stimulate the evolution towards a stable pattern of geographical clustering.

\section{Reconfiguration of Socio-Spatial Embeddedness}

Another important spatial manifestation of renewable energy development and transition is a reconfiguration process of local socio-spatial arrangement, which encompasses the economic, material and cultural aspects of local or regional energy systems [23-25]. From the perspective of geography of transition, Bridge et al. (2013) view the pre-existing spatial embeddedness and path dependency of a specific energy technology as obstacles to the development of alternative technology. Using the term of "spatial embeddedness," Bridge et al. (2013) define it as "both the sunk costs of capital investment (represented by the built environment and the infrastructures of energy capture, conversion and consumption), and the place-based cultures of consumption that surround certain energy technologies (expressed, for example, in expectations and norms about the cost and reliability of supply, or the social practices associated with energy consumption)" (p. 338-339) [5]. Adapting from Bridge et al.'s conceptualization, we regard new configurations of local socio-spatial arrangements as outcomes for the anchoring of renewable energy technologies into local contexts. This anchoring process can be represented through two aspects: (1) the built environment and the infrastructure system; (2) the culture, and social practices and norms associated with energy consumption.

\section{Energy Infrastructure and the Built Environment}

In the past decade, although China has witnessed rapid growth of solar photovoltaic (PV) and wind power installation capacities, the problem of the so-called "wind and solar power abandonment" is also getting serious [26]. This situation is mainly caused by the lack of grid infrastructure connected to newly built large-scale wind farms or solar PV power stations. Just until recently, the central government starts to turn their attention to the construction of grid, so as to bridge the huge gap between installation capacities and electricity generation. In the "13th Five-Year Development Plan for Wind Power", nine large-scale projects of grid construction are proposed, which are aimed to connect current wind farms [27]. For concentrated renewable energy power stations that are usually located far away from the main energy consumption areas, construction of new energy infrastructures seems to be an inevitable mission, which requires massive investment (represented as sunk cost of renewable energy development) and leads to certain degree of lock-in.

As regard to the distributed renewable energy development, there are a few studies that have shed some light on the relationship of renewable energy and infrastructure by situating the application of certain renewable energy within the contexts of urban or regional level. For example, several papers documented the popularization of solar water heater (SWH) in Shandong Province [18, 20, 28]. Although in these studies more focuses are placed upon the economic and social aspects of development, the penetration of SWH into the built environment is also reflected. On the other hand, successful cases of building-integrated SWH are frequently reported in public media, ${ }^{1}$ representing strong evidences on how SWH are integrated into newly built residential buildings across China. Figure 1 shows a reconfiguration of the urban landscape in Shandong by three typical types of buildingintegrated SWH or solar water heating system (SWHS).

\footnotetext{
${ }^{1} \mathrm{http} / / /$ www.szzjw.gov.cn/html/xinwenzhongxin/xitongdongtai/20161216/ 4821.html; http://www.chinasolarcity.com.cn/n16528755/c17392349/content. html
} 
Fig. 1 Typical landscapes of residential buildings integrated with SWH/SWHS in Shandong (Source: pictures taken by the first author, October 2016)

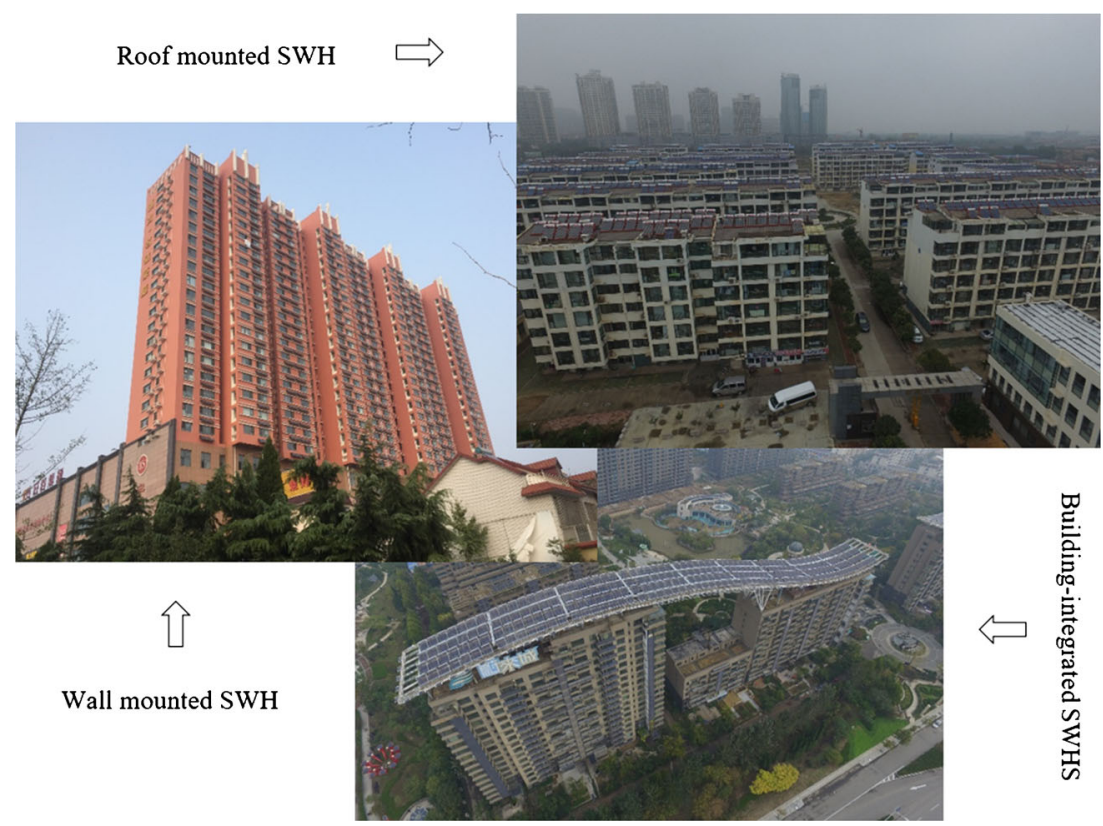

\section{The Place-Based Cultures of Consumption that Surround Certain Energy Technologies}

Besides physical environment, energy transitions also get embedded into local consumption culture and social practices. Relating to this, Liu et al. (2013) introduced an interesting "social practice approach" in their investigation of rural households' energy consumption in China [29]. Originating from sociology, this approach regards households' daily practices such as cooking, water heating, and transportation as sources of energy consumptions. When a renewable energy transition is taking place, residents' daily practices are also reconfigured around the new energy technology, which is the so-called "anchoring" process. This perspective is important since it captures the place-based social dimensions of an energy transition. For instance, in the aforementioned Shandong's case of solar energy development, it is reported that in many rural areas the possession of a SWH is regarded as a symbol of some kind of social status, and it is even listed as one of the "must-have items" for a marriage, just as color TV and washing machines. ${ }^{2}$ This is a typical case for the reconfiguration process of residents' consumption culture and the embeddedness of solar energy into the local contexts. However, since Liu et al. (2013), there are rarely any empirical studies adopting this perspective in the investigation of China's sustainable energy transitions, which urgently needs more attention.

Overall, spatial clustering and socio-spatial embeddedness represent two mechanisms as well as outcomes of renewable energy transitions. These two branches of dynamics

\footnotetext{
${ }^{2}$ http://www.gov.cn/jrzg/2008-09/20/content_1100765.htm
}

sometimes reinforce each other during a transitional process. On the one hand, spatial clustering of industries might foster various entrepreneurial activities (for instance legitimacy building), which act as strong impetus for further reconfiguration of spatial embeddedness. In the case of SWH development in Dezhou city in Shandong, the industrial agglomeration gave birth to a prosperous localized innovation environment, which nurtures the development of peripheral industries. For instance, as the leading enterprise in the solar industrial cluster, Himin invested heavily in projects such as Solar Valley and Utopia Garden, which have brought about largescale changes in urban landscapes. It is through these pioneering activities from local enterprises that SWH is quickly and firmly embedded into local contexts. On the other hand, locally embedded socio-spatial elements may create some kind of incubator environment for emergence or development of industrial clusters. This can best be represented through the development of industrial parks in many cities in China, in which infrastructure construction (reconfiguration of build environment) is often conducted by local government as a means to attract related enterprises and foster industrial agglomeration.

\section{Conclusion and Discussion}

The past decade has witnessed rapid growth of the renewable energy sectors in China. From a geographical perspective, this article presents recent developments of renewable energy in China, manifested through the formation of spatial clusters on the one hand, and reconfiguration of socio-spatial embeddedness on the other. We adopt this geographical 
perspective since in transition studies, especially those on China's energy transitions, certain important dimensions have long been neglected. Our literature review clearly uncovers this research gap, in which scant attention has been paid to the reconfigurations of place-specific arrangements, especially the social and cultural dimensions.

As for the spatial clustering of renewable energy industries, two typical clusters for solar and wind energy respectively are presented in this study: the solar industry cluster in Shandong province, and the wind industry cluster in Jiangsu province. We highlight these two cases since the formation and evolution of the industry clustering represent different mechanisms. In the Shandong case, a bottom-up formation process can be observed, in which the role of pioneering enterprises is imperative. While in the Jiangsu case, top-down planning initiated by the local governments is believed to be a strong enabling factor in the development and evolution of clusters. Compared to the spatial clustering, the reconfiguration of socio-spatial embeddedness has received much less attention. Although profound changes have been engendered in energy infrastructures and the built environment nationwide, to our surprise, these transformations are seldom documented in energy transition studies. This is especially the case when it comes to people's consumption culture and social practices, which is an indispensable aspect of energy transitions, whereas it can be easily taken for granted. Therefore, this study tries to bring together scattered evidence available in extant literature as well as various internet sources in an attempt to draw a rough sketch of continuous reconfigurations of local sociospatial arrangements in China. It is hoped that this research can act as a catalyst to encourage more in-depth research from this socio-spatial perspective, so as to reach a more concrete understanding of current wave of energy transitions in China.

As noted by Bridge et al. (2013), how and to what degree certain energy is embedded in local contexts exhibits wide geographical variations [5]. We also observe substantial spatial disparities in the development of renewable energies in China that exist between different regions. In the national planning for the development of solar and wind power, the whole nation is divided into six regions (North, South, Central, East, Northwest, and Northeast). In general, the three northern regions (North, Northwest, and Northeast) are rich in renewable energy resources; as such, they mainly play the role of resource supply areas. While the Central, East, and South regions are rich in financial and human resources, and they are more likely to foster industry clustering and upgrading. As pointed out by Dong et al. (2016), this regional disparity is a unique feature in China, compared with other developed countries [21].

As argued above, the spatial dimension is an important facet of energy transitions. However, there are very rare empirical studies researching renewable energy transitions in China from this perspective. In light of this, we propose two avenues for future research. Firstly, following the observation of different clustering patterns (bottom-up and top-down) of renewable energy industry, future studies should explore why these clustering patterns emerge in a certain region but not in another, how these clusters evolve, and what implications these cases of clustering have for other regions in China or other latecomer countries. Secondly, future research should pay more attention to the reconfiguration of socio-spatial arrangements that is induced by the embeddedness of renewable energy into certain places. More specifically, in-depth analysis is needed in uncovering how renewable energy application and popularization shape socio-spatial arrangements in economic, physical, social and cultural aspects, such as energy infrastructure, the built environment, social practices, and consumption culture.

Acknowledgements This research did not receive any specific grant from funding agencies in the public, commercial, or not-for-profit sectors.

\section{Compliance with Ethical Standards}

Conflict of Interest Ping Huang declares no conflict of interest. Ying Liu declares no conflict of interest.

Human and Animal Rights and Informed Consent This article does not contain any studies with human or animal subjects performed by any of the authors.

Open Access This article is distributed under the terms of the Creative Commons Attribution 4.0 International License (http:// creativecommons.org/licenses/by/4.0/), which permits unrestricted use, distribution, and reproduction in any medium, provided you give appropriate credit to the original author(s) and the source, provide a link to the Creative Commons license, and indicate if changes were made.

\section{References}

1. Bergek A, Hekkert M, Jacobsson S, et al. Technological innovation systems in contexts: conceptualizing contextual structures and interaction dynamics. Environmental Innovation and Societal Transitions. 2015;16:51-64.

2. Geels F, Schot J. Typology of sociotechnical transition pathways. Res Policy. 2007;36:399-417.

3. Hekkert MP, Suurs RAA, Negro SO, et al. Functions of innovation systems: a new approach for analysing technological change. Technol Forecast Soc Chang. 2007;74:413-32.

4. Smith A, Voß JP, Grin J. Innovation studies and sustainability transitions: the allure of the multi-level perspective and its challenges. Res Policy. 2010;39:435-48.

5. Bridge G, Bouzarovski S, Bradshaw M, et al. Geographies of energy transition: space, place and the low-carbon economy. Energy Policy. 2013;53:331-40.

6. Truffer B, Coenen L. Environmental innovation and sustainability transitions in regional studies. Reg Stud. 2012;46(1):1-21.

7. Negro S, Vasseur V, van Sark W, et al. Solar eclipse: the rise and 'dusk' of the Dutch PV innovation system. International Journal of Technology, Policy and Management. 2012;12(2-3):135-57. 
8. Huang P, Negro SO, Hekkert MP, et al. How China became a leader in solar PV: an innovation system analysis. Renew Sust Energ Rev. 2016;64:777-89.

9. Rutherford J, Coutard O. Urban energy transitions: places, processes and politics of socio-technical change. Urban Stud. 2014;51(7): 1353-77.

10. Wieczorek A, Raven R, Berkhout F. Transnational linkages in sustainability experiments: a typology and the case of solar photovoltaic energy in India. Environmental Innovation and Societal Transitions. 2015;17:149-65.

11. National Development and Reform Commission of China (NDRCC). The 12th Five-Year Development Plan for Renewable Energy. 2012.

12. National Development and Reform Commission of China (NDRCC). The 13th Five-Year Development Plan for Renewable Energy. 2016.

13. Lo K. A critical review of China's rapidly developing renewable energy and energy efficiency policies. Renew Sust Energ Rev. 2014;29:508-16.

14. Ming Z, Ximei L, Yulong L, et al. Review of renewable energy investment and financing in China: status, mode, issues and countermeasures. Renew Sust Energ Rev. 2014;31:23-37.

15. Elola A, Parrilli MD, Rabellotti R. The resilience of clusters in the context of increasing globalization: the Basque wind energy value chain. Eur Plan Stud. 2013;21(7):989-1006.

16. He Z, Xu S, Shen W, et al. Overview of the development of the Chinese Jiangsu coastal wind-power industry cluster. Renew Sust Energ Rev. 2016;57:59-71.

17. Holmgren KM, Andersson E, Berntsson T, Rydberg $\mathrm{T}$. Gasification-based methanol production from biomass in industrial clusters: characterisation of energy balances and greenhouse gas emissions. Energy. 2014;69:622-37.

18. Schroeder PM, Chapman RB. Renewable energy leapfrogging in China's urban development? Current status and outlook. Sustainable Cities and Society. 2014;11:31-9.
19. Hu R, Sun P, Wang Z. An overview of the development of solar water heater industry in China. Energy Policy. 2012;51:46-51.

20. Li W, Song G, Beresford M, et al. China's transition to green energy systems: the economics of home solar water heaters and their popularization in Dezhou city. Energy Policy. 2011;39(10):5909-19.

21. Dong L, Liang H, Gao Z, et al. Spatial distribution of China's renewable energy industry: regional features and implications for a harmonious development future. Renew Sust Energ Rev. 2016;58:1521-31.

22. Ter Wal AL, Boschma R. Co-evolution of firms, industries and networks in space. Reg Stud. 2011;45(7):919-33.

23. Mendoza JMF, Sanyé-Mengual E, Angrill S, et al. Development of urban solar infrastructure to support low-carbon mobility. Energy Policy. 2015;85:102-14.

24. Wang X, Lim MK, Ouyang Y. Infrastructure deployment under uncertainties and competition: the biofuel industry case. Transp Res B Methodol. 2015;78:1-15.

25. Ravi S, Lobell DB, Field CB. Tradeoffs and synergies between biofuel production and large solar infrastructure in deserts. Environmental science \& technology. 2014;48(5):3021-30.

26. Zhao HR, Guo S, Fu LW. Review on the costs and benefits of renewable energy power subsidy in China. Renew Sust Energ Rev. 2014;37:538-49.

27. National Development and Reform Commission of China (NDRCC) and National Energy Administration (NEA). The 13th Five-Year Development Plan for Wind Power. 2016.

28. Goess S, De Jong M, Ravesteijn W. What makes renewable energy successful in China? The case of the Shandong province solar water heater innovation system. Energy Policy. 2015;86:684-96.

29. Liu W, Spaargaren G, Heerink N, et al. Energy consumption practices of rural households in north China: basic characteristics and potential for low carbon development. Energy Policy. 2013;55: $128-38$. 